\title{
LAND USE AND TEA PLANTATION LANDSCAPE CHARACTERISTICS AND CORRELATION ANALYSIS ALONG THE ELEVATION GRADIENTS IN LANCANGJIANG CATCHMENT OF YUNNAN IN CHINA
}

\author{
ZENG, W. J. ${ }^{1,2}$ - FAN, K. ${ }^{1,2}$-ZHANG, J. S. ${ }^{1,2}$-WANG, J. X. ${ }^{1}$-ZHENG, H. G. ${ }^{1,2}-$ CHEN, Y. C. ${ }^{1,2}$ \\ LI, J. H. ${ }^{1,2^{*}}$ \\ ${ }^{1}$ College of Water Conservancy, Yunnan Agricultural University, Kunming, China \\ ${ }^{2}$ Engineering Research Center of Science and Technology of Land and Resources, Yunnan \\ Agricultural University, Kunming, China \\ *Corresponding author \\ e-mail:28038071@qq.com
}

(Received $19^{\text {th }}$ Jun 2019; accepted $16^{\text {th }}$ Oct 2019)

\begin{abstract}
Land use in this study of the landscape, the spatial, statistical and comparative analysis is carried out on the tea plantation in Lancangjiang Catchment of Yunnan in China and its other main land use typesin perspective of the elevation gradient by using the GIS and data analysis software. The result shows that the landscape index is invert "V" or invert "U"-shaped, or decreasing linearly along the elevation gradient. The peak appears between 1200 and $1800 \mathrm{~m}$ with the highest concentration and spatial heterogeneity. Therefore, the tea plantation area is the largest and the tea planting is most active in this range. On the contrary, the bottom value appears at the elevation below $600 \mathrm{~m}$ or above $2600 \mathrm{~m}$. Therefore, it holds the least area of the tea plantation. The four main land use types are weakly correlated with the tea plantation landscape, and the construction land use has the weakest correlation. Except for the grassland, the correlation between the tea plantation and other land use types is mainly reflected in the landscape area, the landscape shape index and the landscape agglomeration index. The research might be helpful for optimizing the land use landscape and improving the ecological conditions in the catchment.
\end{abstract}

Keywords: land use, tea plantation, landscape index, development trend, correlation

\section{Introduction}

Land is an important resource and a requisite for our living and development. In recent years, with the rapid increase of the world population and the accelerated urbanization, the land use by human beings is expanding in scope and depth. The socio-economic development is accompanied by the big change of the land cover, and it leads to a series of ecological problems. With the development of the landscape ecology, the landscape pattern analysis has become one of the effective technical ways to study the spatial structure and evolution of the land use (Chen, 2014). Tea is the traditional and main cash crop in Yunnan, and the Lancangjiang Catchment has the longest history of planting tea due to its preferable natural conditions. It also has the largest area of the tea plantation. With the rapid development of Pu'er Tea and increasing tea price, the tea production and the scale of the tea plantation has been expanding. It brings great impact on the ecological environment of the catchment. At the macro level, it disturbs and influences the number, area, shape and distribution of the patches of the land use landscape. Therefore, it is of great significance to carry out the tea plantation landscape research in order to optimize the land use landscape and improve the ecological conditions in the catchment. 
The current land use research in the world covers the relationship of the land use and the climate change (Pavani, 2018; Furlanetto, 2018), the significance of the land use research to the (paleo) environment research (Jaeschke, 2018), the land use scheme (Martyn et al., 2017), and the drivers of the land use (Cattarino, 2014). The tea garden research is more focused on the livelihoods of the tea farmers (Biggs, 2018). There has been a lot of the tea research being done in the Lancangjiang Catchment, but most is about the main ingredients of the tea (Tan, 2012; Gong, 2010), heavy metal pollution (Chen, 2011; Liu, 2008), spectroscopic identification (Ning, 2013, 2010; Zheng, 2013), soil nutrients in the tea plantation (Gao, 2013; Yi, 2011; Li, 2011), and so on. Many of the research are aimed to improve the tea production and quality, so they focus on its quality control, physio-chemical properties of the soil and its impact on the tea. More research has been done on the vegetation cover (Fan, 2012) and land use (Wang, 2008) of the catchment than the spatial distribution and landscape of the tea plantation. For the landscape research, more is done on the land use, the urban area (Chu, 2018), the green park (Fan, 2018), lakes and wetlands (Zhai, 2018; Pu, 2018; Zhang, 2019), much less about the tea plantation. The change with time is more studied than the change with the elevation gradients for the land use and the landscape characteristics.

In this paper, the landscape study is carried out on the tea plantation and other main land use types (farmland, forest land, grassland, construction land) in Lancangjiang Catchment (Yunnan Section), in perspective of the elevation gradient by using the GIS and data analysis software, and by conducting the spatial, statistical and comparative analysis. The research might be helpful for optimizing the land use landscape, adjusting the agricultural structure and improving the ecological conditions in the catchment.

\section{Materials and methodologies}

\section{Brief introduction of the study area}

Lancang-Mekong River is a famous international river, and the only one river connecting the six countries in Asia. It originates in the northwest of Zaduo County of Yushu Tibetan Autonomous Prefecture of Qinghai Province in China (Fig. 1). The Yunnan Section of the river sets between N21 $08^{\prime} 41^{\prime \prime} \sim 29^{\circ} 14^{\prime} 04^{\prime \prime}$ (Fig. 1). Lancangjiang River flows $1240 \mathrm{~km}$ long in Yunnan Province, with a catchment area of 90,000 $\mathrm{km}^{2}$, covering Diqing, Lijiang, Dali, Baoshan, Lincang, Pu'er and Xishuangbanna prefectures. The catchment is going from north down to the south, and its water system is shaped as a broom. The difference of the elevation in the Catchment is big, and the temperature and precipitation are increasing from the north to the south. The dry and wet seasons are distinctive, the wet season starting from May to October, and the dry season starts from November to April of the next year. More than $85 \%$ of the rainfall concentrates in the wet season. There are various vegetation types in the catchment, including the tropical rainforest, monsoon forest and mountainous grassland. The topographic landform and climate of the catchment provides the preferable natural conditions for the tea production. The increasing tea plantation brings great economic benefits for the local society, but the unplanned expansion of the tea plantation brings many environmental issues as well.

\section{Data source and processing}

The current land use data for the research is obtained from the remote sensing images of Landsat8, taken in 2017, with a resolution of $30 \mathrm{~m}$. DEM (Digital Elevation Model) 
data is the original data from SRTMDEM 90M. The original images come from the Geospatial Data Cloud Platform of Chinese Academy of Science, and the land use and elevation data is drawn out by ENVI5.1 and ArcGIS10.0. The zoning maps of the latitude, elevation and climate are the research outputs of the Land Resources Science, Technology and Engineering Research Center of Yunnan Agricultural University. The downloaded 13 images are calibrated by ENVI5.1 and the Band 5, 4, 3 images are fused with standard false color based on the enhanced processing. The training samples are selected based on the terrain feature in the field to supervise the classification and its accuracy. Except for the main research target - the tea plantation, the other six land use types are interpreted according to the Current Land Use Classification Standard (GB/T 21010-2007) such as farmlands, forest lands, grasslands, construction lands, water and other land uses (including idle land, barren rocky land, garden). The final classification is finished after blurring, mosaic method processing and range-cutting (Figs. 2 and 3). Then the land use type and area data are furthermore extracted by ARCGIS10.0 (Table 1).

In order to differentiate the tea garden from the forest land, a modified decision tree classification method is applied. The elevation and slope degree which affect the tea garden growth have been used as decision principles, combined with the spectral characteristics of the tea garden and forest land. The ratio index, NDVI value and the texture index are introduced into the decision classification, and the decision tree remote sensing data extraction model is established to improve the accuracy of the remotely sensed image classification.

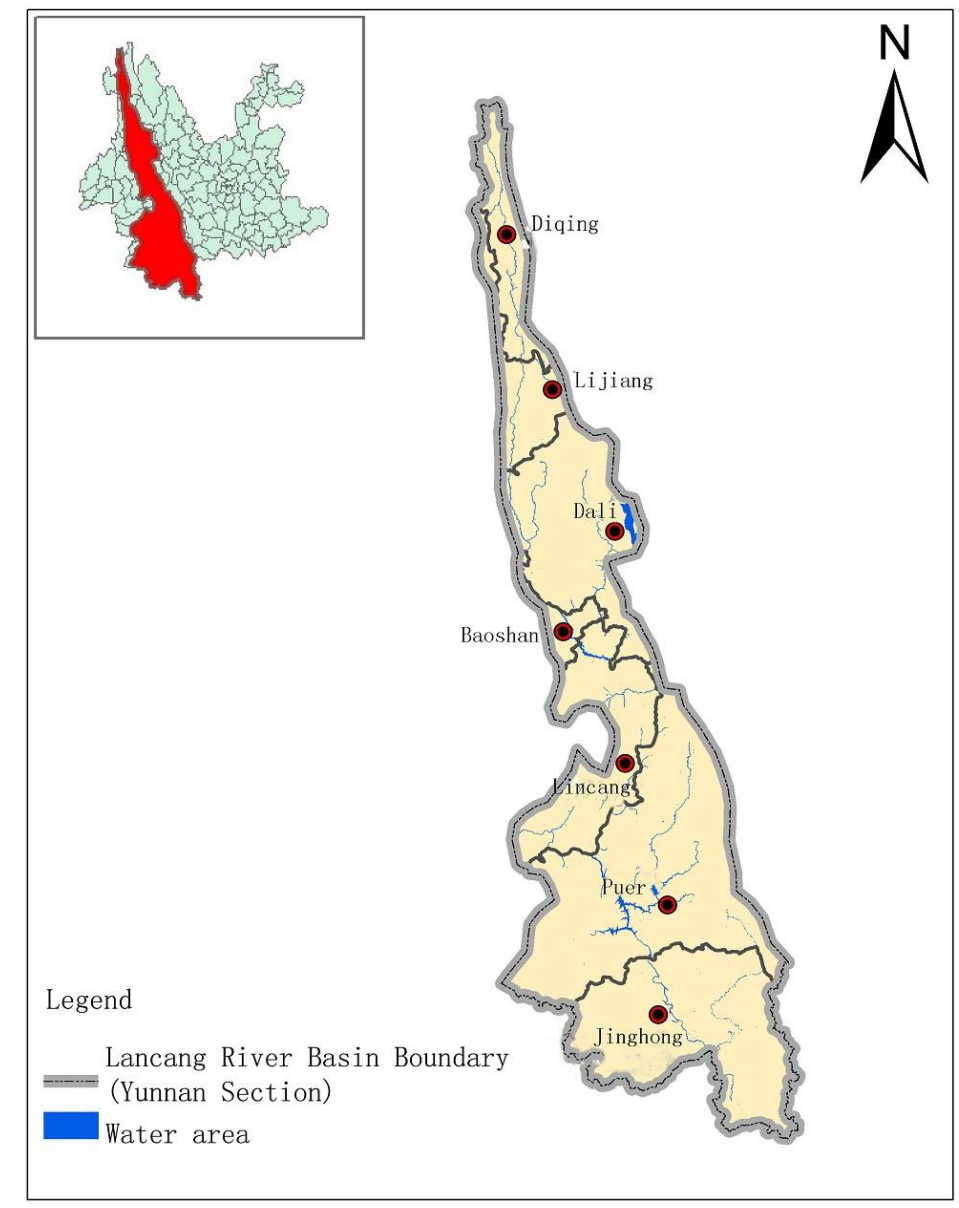

Figure 1. Location of the study 


$$
-14896 \text { - }
$$

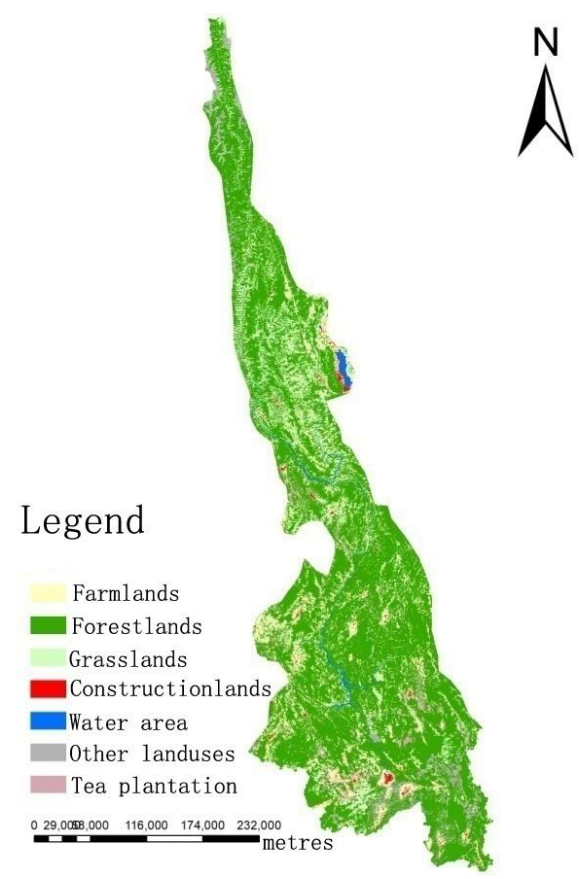

Figure 2. The map of remote sensing classification

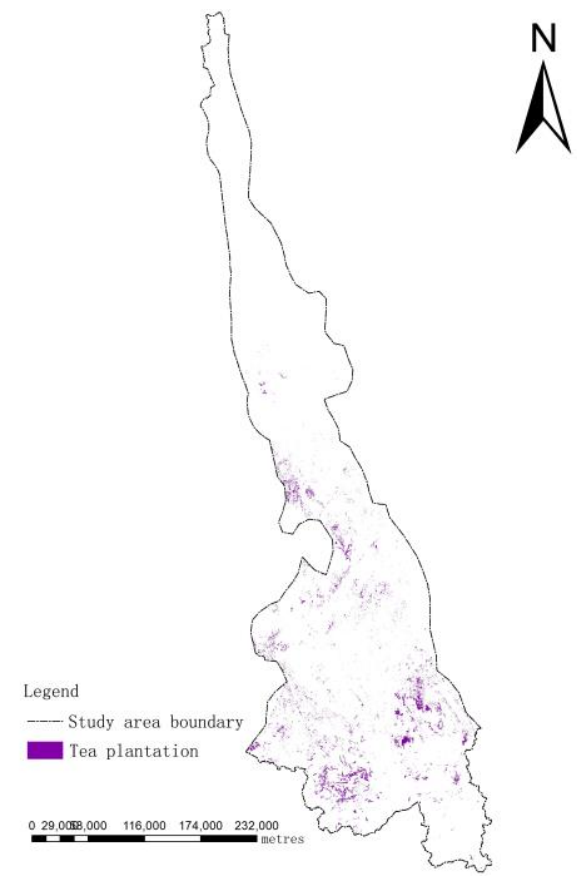

Figure 3. The map of tea garden distribution

\section{Research methods}

According to the landscape pattern theory, the landscape pattern index is calculated and the pattern of the tea plantation under different elevation gradient and land use is analyzed by spatially overlaying the different map layers. The Fragstats 4.2 is applied in this process. 


$$
-14897 \text { - }
$$

Table 1. The information of the remote sensing classification

\begin{tabular}{c|c|c|c|c}
\hline Land type & Patch quantity & Patch ratio (\%) & Area/hm & Area ratio (\%) \\
\hline Farmland & 64729 & 25.65 & 1198777.76 & 13.64 \\
Forest land & 31724 & 12.57 & 6061472.32 & 68.96 \\
Grassland & 71281 & 28.25 & 803689.18 & 9.14 \\
Constn land & 19671 & 7.8 & 82587.01 & 0.94 \\
Water area & 2234 & 0.89 & 101375.14 & 1.15 \\
Other land & 29141 & 11.55 & 327609.13 & 3.73 \\
Tea plant & $\mathbf{3 3 5 4 2}$ & $\mathbf{1 3 . 2 9}$ & $\mathbf{2 1 4 2 8 2 . 9 5}$ & $\mathbf{2 . 4 4}$ \\
Total & 252322 & 100 & 8789793.49 & 100 \\
\hline
\end{tabular}

There are tens of indexes currently used for studying the landscape pattern (Zhao, 2007), out of which, eight indexes are selected. They are landscape type area (CA), proportion of landscape type area (PLAND), average patch area (AREA_MN), patch area standard deviation (AREA_SD), largest patch index (LPI), patch density (PD), landscape shape index (LSI), landscape agglomeration index (AI).

\section{(1) Class area}

$\mathrm{CA}$ is the total area of a certain landscape patches, with measurement unit of $\mathrm{hm}^{2}$. In ecological terms, it reflects the energy storage and energy flow of a certain landscape type. The bigger the patch area the more abundant its species, and the faster energy flow. The formula is as follows (Eq. 1):

$$
C A=\sum_{j=1}^{n} a_{i j}
$$

in which, $a_{i j}$ is the area of Patch $\mathrm{j}$ of Type $\mathrm{i}, \mathrm{n}$ is the quantity of the patches.

\section{(2) Proportion of landscape type area (PLAND)}

PLAND is the proportion of the patch area of certain landscape in the whole landscape area, expressed by "\%", showing the dominance or importance of certain landscape type in the whole landscape. The formula is shown as follows (Eq. 2):

$$
\text { PLAND }=\frac{\sum_{j=1}^{n} a_{i j}}{A} \times 100
$$

In this equation, " $\mathrm{A}$ " is the total area of the landscape; " $a_{i j}$ " is the area of the Patch $\mathrm{j}$ of the Landscape Type $i$; " $n$ " is the number of the patches.

\section{(3) Average patch area (AREA_MN)}

AREA_MN is the average area of all the patches of a certain landscape type. The change of its value gives more ecological information of the landscape, and it is a critical index in reflecting the landscape heterogeneity. The formula is shown as follows (Eq. 3): 


$$
A R E A_{-} M N=\frac{A_{i}}{N_{i}}
$$

In this equation, "Ai" is the total area of the Landscape Type $\mathrm{i}$; "Ni" is the number of the patches of the Landscape Type $i$.

\section{(4) Patch area standard deviation (AREA_SD)}

AREA_SD is the standard deviation of all the patch area of a certain landscape type. It reflects the diffusion degree of the patch area of a certain landscape type and the variation degree of the landscape patch scale. The bigger the value, the higher degree of the variation. The formula is as follows (Eq. 4):

$$
A R E A_{-} S D=\sqrt{\frac{\sum_{j=1}^{n}\left(a_{i j}-\frac{A_{i}}{N_{i}}\right)}{N_{i}}}
$$

In this equation, " $a_{i j}$ " is the area of Patch $j$ of the landscape type $i$; " $n$ " is the number of the patches. "Ai" is the total area of the Landscape type I; "Ni" is the total number of the patches of the Landscape type $i$.

\section{(5) Largest patch index (LPI)}

LPI is the proportion of the largest patch area of a certain landscape type in the whole landscape area. It shows the dominance of a certain landscape type in the whole landscape. Its value reflects the intensity of the human activity. The formula is as follows (Eq. 5):

$$
L P I=\frac{\operatorname{Max}\left(a_{i j}\right)}{A} \times 100
$$

In this equation, "Max $\left(a_{\mathrm{ij}}\right)$ " is the area of the largest patch of the landscape type $\mathrm{i}$; " $\mathrm{A}$ " is the total area of the whole landscape.

(6) Patch density (PD)

PD is the ratio of the patch number of a certain landscape type in the whole landscape area, in other words, the patch quantity in each hectare. It shows the fragmentation of the landscape. The bigger the value, the more fragmented the landscape, thus the more complicated spatial structure of the landscape. The formula is as follows (Eq. 6):

$$
P D=\frac{N_{i}}{A}
$$

In this equation, "A" is the total area of the whole landscape, and " $\mathrm{N}$ " is the patch quantity of the landscape type $i$. 


\section{(7) Landscape shape index (LSI)}

LSI is the shape of a certain landscape type, and is generally used to indicate the complexity and stability of the landscape. When the landscape patch shape is close to a square, the value of LSI is close to 1 . When the shape is complex or becoming elongated, the value will be increased infinitely. The formula is as follows (Eq. 7):

$$
L S I=\frac{0.25 E}{\sqrt{A}}
$$

In this equation, " $\mathrm{A}$ " is the total area of the whole landscape, and " $\mathrm{E}$ " is the total length of all the patch boundaries in the landscape.

\section{(8) Agglomeration index of landscape (AI)}

"AI" is the agglomeration degree of the patches in a certain landscape type. Its value ranges from 0 to 100 . The bigger the value, the higher degree of agglomeration of the patches. The formula is as follows $(E q .8)$ :

$$
A I=\frac{g_{i i}}{\operatorname{Max} \rightarrow g_{i i}} \times 100
$$

In this equation, "g $\mathrm{g}_{\mathrm{ii}}$ " is the number of similar patches jointing each other of the landscape type $\mathrm{i}$.

When the index values of the landscape pattern are obtained, the correlation between the tea plantation and other land use types is analyzed, in other words, the relative variants are analyzed to find out to which extent they are related to each other. Pearson correlation coefficient is used for the analysis and the formula is shown below (Eq. 9) (Zhang, 2014):

$$
r=\frac{l_{X Y}}{\sqrt{l_{X X} l_{Y Y}}}=\frac{\sum(X-\bar{X})(Y-\bar{Y})}{\sqrt{\sum(X-\bar{X})^{2} \sum(Y-\bar{Y})^{2}}}
$$

In which, $\mathrm{r}$ is correlation coefficient of variants; $|\mathrm{r}|$ is the degree the two variants are related, when $r>0$ means positive correlation, $r<0$ for negative, $r=0$ means zero correlation. The closer the value of $|\mathrm{r}|$ to 1 , the higher the correlation degree. More specifically, when $|\mathrm{r}|$ is $0.8 \sim 1$, very strong correlation; $0.6 \sim 0.8$ is strong; 0.4 0.6 is medium; 0.2 0.4 is weak; $0.0 \sim 0.2$ is very weak or no relation.

The correlation coefficient needs to be tested by the prominence value $(\mathrm{P})$. When $\mathrm{P} \leq 0.05$, it has prominent correlation. SPSS 22 is used in this process. In the " $\mathrm{r}$ " value results, "*" means at $p \leq 0.05$, and "**" means at $p \leq 0.01$. There exists certain deviation in the correlation results due to the limited amount of the data sample, so the prominence of the correlation is only done for those at $\mathrm{p} \leq 0.01$.

\section{Results and analysis}

Table 1 shows that as far as the patch quantity is concerned, grassland $>$ farmland $>$ tea plantation $>$ forest land $>$ other land $>$ construction land $>$ water area, and the grassland is 
the most, holding a proportion of 0.2825 ; and the water area is the least, holding 0.0089 . The tea plantation patches, preceded by the grassland and farmland, is ranked the third, holding 0.1329 . In respect of the type area, it is forest land $>$ farmland $>$ grassland $>$ other land use $>$ tea plantation $>$ water area $>$ construction land. The forest land has the largest area in the whole catchment, its proportion is as high as 0.6896 . The construction land has the least area with a portion of 0.0094 . The tea plantation, with a portion of 0.0244 , stands at the fifth place (Figs. 2 and 3).

\section{Tea plantation landscape pattern features under different elevation gradients and land use}

There is a wide elevation range in Lancangjiang Catchment (Yunnan Section) running from 460 to $6456 \mathrm{~m}$. In order to accurately display the change of the tea plantation landscape pattern under different elevation gradients and land uses, the elevation is graded every $200 \mathrm{~m}$ by equal- or non-equal spacing methods to include 14 gradients. They are below $600 \mathrm{~m}, 600 \sim 800 \mathrm{~m}, 800 \sim 1000 \mathrm{~m}, 1000 \sim 1200 \mathrm{~m}$, $1200 \sim 1400 \mathrm{~m}, \quad 1400 \sim 1600 \mathrm{~m}, 1600 \sim 1800 \mathrm{~m}, 1800 \sim 2000 \mathrm{~m}, 2000 \sim 2200 \mathrm{~m}$, $2200 \sim 2400$ m, 2400 2600 m, 2600 2800 m, 2800 3000 m, above $3000 \mathrm{~m}$ (Fig. 4). The statistical data of the land types is collected after graphic overlaying of the RS image classification map and latitude change map. Then after cutting and transferring to the grid data, they are introduced to Fragstats for the landscape pattern index. It is exhibited in Table 1 that there is no tea plantation above $2800 \mathrm{~m}$, so it is only needed to analyze the pattern features below $2800 \mathrm{~m}$.

\section{Landscape pattern features of main land use types at different elevation}

By overlaying the land use map and elevation map with Arcgis 10.0, each level is converted into ESRI grid format, and the land use landscape pattern index under different elevation is calculated with Fragstats4.2 (Fig. 5).

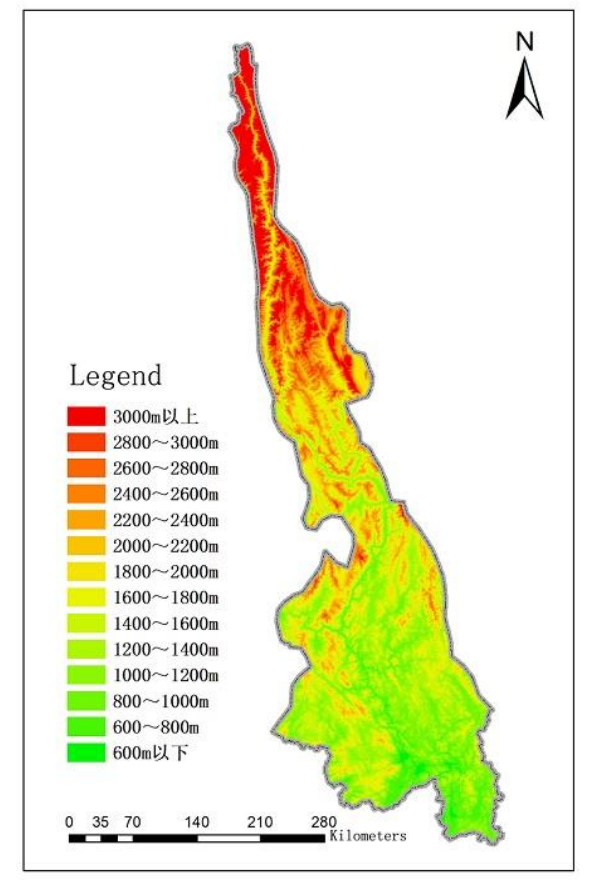

Figure 4. The map of altitude gradient 

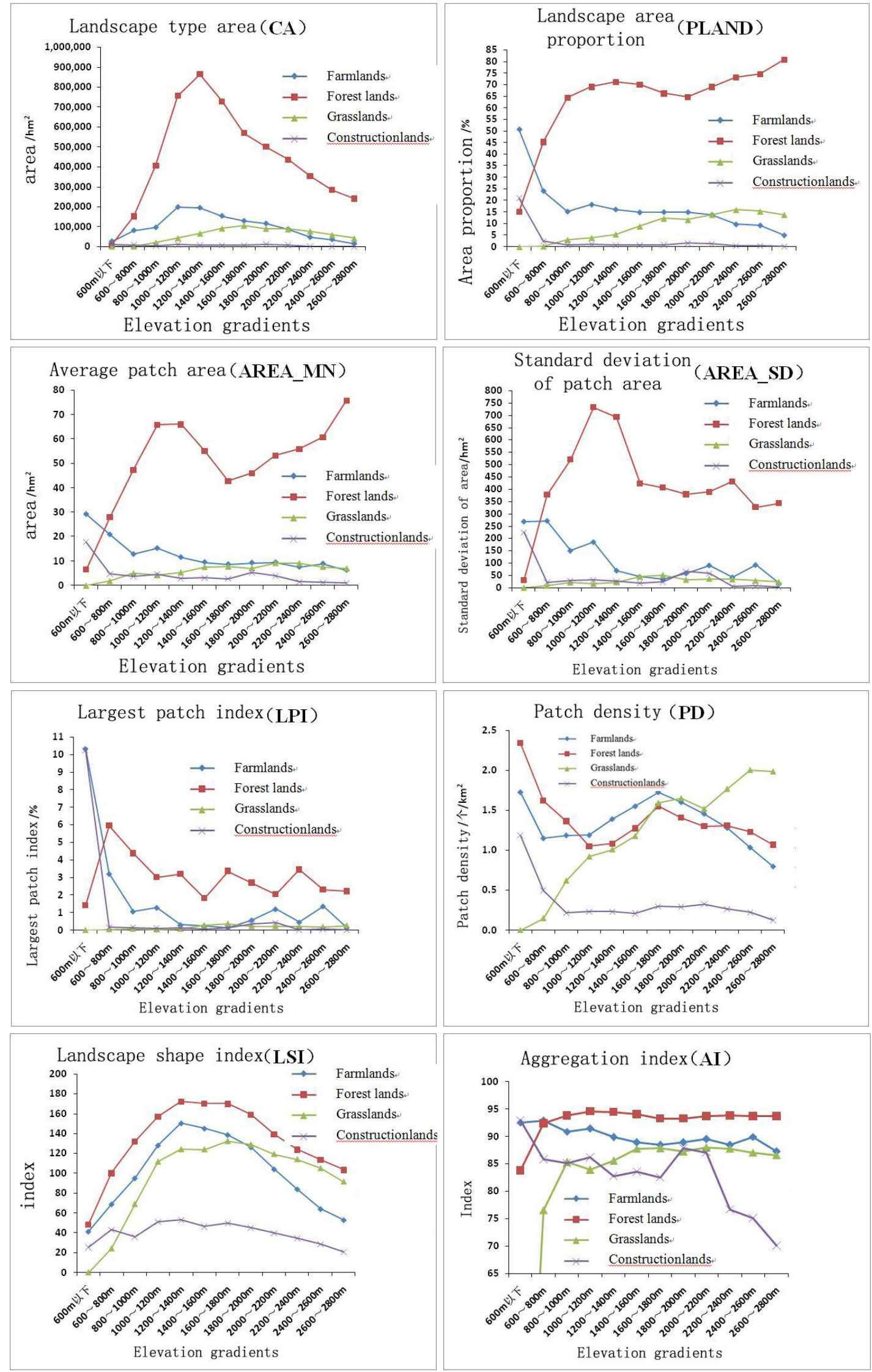

Figure 5. Landscape pattern index of land use type in different altitude gradient 
As far as the landscape area (CA) is concerned, when the elevation is increasing, the farmland, forest land and the grassland is going up and down, and the construction land use is generally decreasing. In respect of landscape area proportion (PLAND), the forest land experiences rapid increase first and then gradual decrease, while the grassland keeps going up mildly, and the farmland and the construction land use experience the slow and then the fast climb-up. For the average area of the patch (AREA_MN), the forest land fluctuates but keeps going up; the grassland is increasing gradually; the farmland and the construction land keep declining from a fast to a slow speed. In respect of the standard deviation of the patch area (AREA_SD), the forest land stays stable after an up-and-down; the farmland is declining with a wave shape; the construction land experiences a steep downward and then keeps stable, and the grassland generally stays constant with little change. In respect of LPI, the forest land fluctuates, the farmland and the construction land experience a steep downward and then keeps stable, and the grassland has little change. In respect of the patch density (PD), the forest land, the farmland and the construction land go from a fast to a gentle downward, the grassland is fluctuating to an upward. The landscape shape index (LSI) shows that the farmland, the forest land, the grassland and the construction land first go up and then down, and the construction land is generally declining. In respect of the agglomeration index (AI), the forest land and the grassland go from upward to a stable status, the farmland goes down mildly, and the construction land fluctuates to a downward.

\section{The landscape pattern index of the tea plantation under different elevation}

By overlaying the tea plantation distribution map and the elevation map with Arcgis 10.0, each level is converted into ESRI grid format, and the tea plantation landscape pattern index under different elevation is calculated with Fragstats4.2. The result is shown in Figure 6.

(1) In respect of the landscape type area (CA), with the increasing elevation, the area of the tea plantation goes upward and then downward. The tea plantation area is larger between 1000 and $2000 \mathrm{~m}$, and it is $18.93 \times 10^{4} \mathrm{hm}^{2}$, covering $88 \%$ of the tea plantation area under the research. It is a main area for tea planting. Between 1200 and $1400 \mathrm{~m}$, the tea plantation area is the largest, which is $5.48 \times 10^{4} \mathrm{hm}^{2}$, accounting for $25.71 \%$. The area is reducing below $800 \mathrm{~m}$ or above $2200 \mathrm{~m}$, accounting for only $2.03 \%$. The smallest area of $20.97 \mathrm{hm}^{2}$ is distributed below $600 \mathrm{~m}$, accounting for only $0.01 \%$ of the tea plantation area in the whole catchment.

(2) In respect of the landscape type area proportion (PLAND), with the increasing elevation, the area of the tea plantation goes upward and then downward. The proportion of the tea plantation area is bigger between 1000 and $2000 \mathrm{~m}$, covering 2\% 5\%. Between 1200 and $1400 \mathrm{~m}$, it is the biggest, accounting for 4.52\%, so the tea plantation is dominant in this range. The tea area proportion is decreasing below $800 \mathrm{~m}$ or above $2200 \mathrm{~m}$, accounting for less than $0.5 \%$. The smallest tea area proportion is distributed below $600 \mathrm{~m}$, accounting for only $0.04 \%$.

(3) In respect of the mean area of the patch (AREA_MN), with the increasing elevation, the mean patch area of the tea plantation goes upward and then downward, with mild fluctuation. The larger mean patch area occurs between $800-2000 \mathrm{~m}$, nearly all above $4 \mathrm{hm}^{2}$. It is decreasing below $800 \mathrm{~m}$, nearly all less than $2 \mathrm{hm}^{2}$. The least mean patch area is distributed below $600 \mathrm{~m}$, being only $0.62 \mathrm{hm}^{2}$. It goes up between 2400 and $2600 \mathrm{~m}$, mainly because of the less number of the patches. 

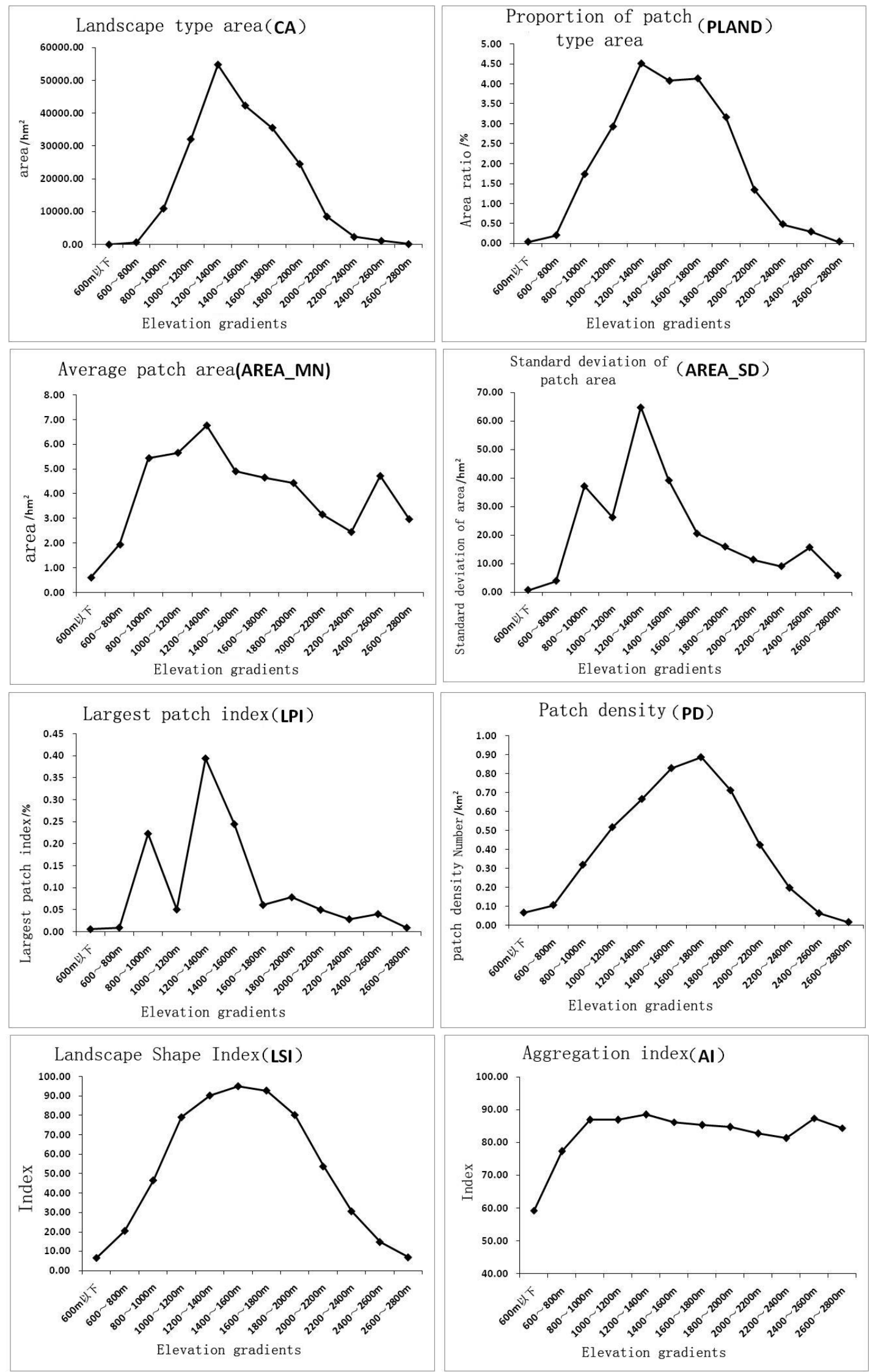

Figure 6. Landscape pattern index of tea garden in different altitude gradient 
4) In respect of the standard deviation of the patch area (AREA_SD), it generally goes from upward to downward with small fluctuation, when the elevation is increasing. The standard deviation is bigger between $800-2000 \mathrm{~m}$, nearly all above $20 \mathrm{hm}^{2}$. It means that, in this range, the patch size is with a higher dispersion, the patch scale is more varied with high spatial heterogeneity. It reaches the highest level between 1200 and $1400 \mathrm{~m}$, getting to $64.87 \mathrm{hm}^{2}$. Then it goes down below $800 \mathrm{~m}$, nearly all less than $4 \mathrm{hm}^{2}$. The least deviation is distributed below $600 \mathrm{~m}$, being only $0.70 \mathrm{hm}^{2}$.

(5) In respect of the largest patch index (LPI), with the increasing elevation, the development trend of the proportion of the largest patch is similar to the standard deviation of the patch area. The LPI is bigger between 800-1000 m and 1200-1600 m, all above $0.2 \%$, so in these ranges the scale of the tea plantation is larger and more dominant. The index is less for the other elevation ranges, less than $0.05 \%$. The least is found below $800 \mathrm{~m}$ or above $2600 \mathrm{~m}$, being only $0.01 \%$.

(6) In respect of the patch density (PD), the density is going up and then down with the increasing elevation. The patches are most densely distributed between 1000 and $2000 \mathrm{~m}$, all above 0.5. In this range, there are most tea plantation patches with the biggest fragmentation and most complex spatial structure. The density is reducing below $600 \mathrm{~m}$ or above $2400 \mathrm{~m}$, all less than 0.1 . The least patch density appears above $2600 \mathrm{~m}$, being only 0.02 .

(7) The landscape shape index (LSI) is going up and then down with the increasing elevation. The shape index has the highest value between 1000 and $2000 \mathrm{~m}$, all above 50 . In this range, the tea plantation patch shape is most complex and irregular. So it is mostly disturbed by est the human activity and has the weakest stability, deviating furthest from the square shape. The lowest index value occurs below $600 \mathrm{~m}$ or above $2400 \mathrm{~m}$, being respectively 6.71 and 6.99 , mainly because of the smallest area of the tea plantation and more regular shape.

(8) The agglomeration index (AI) is going up and then down with the increasing elevation. Its downward trend is not obvious, and the agglomeration degree is generally high. The agglomeration degree is lower below $800 \mathrm{~m}$, being less than 80 . It goes steadily up with little variation above $800 \mathrm{~m}$, with a higher agglomeration degree, being more than 80 .

\section{Correlation of land use type and tea plantation landscape pattern under elevation gradient}

The correlation analysis of the two variants is conducted when the elevation gradient land use type and the tea plantation landscape pattern index are input in SPSS 22 software.

(1) The correlation of the farmland and tea plantation landscape pattern is shown in Table 2. The bolded data with means the variants have closer relation at the layer of $\mathrm{p} \leq 0.01$. From Tables 4 and 5 it is shown that as the elevation changes, the farmland area (CA), the shape index (LSI) and the tea plantation area (CA), the proportion of the tea plantation area (PLAND), the tea patch density (PD) and its shape index (LSI) have strong positive relation, and they have the same relation with the tea average patch area (AM) and the standard deviation of the tea patch area (ASD). So, at the elevation gradient, the farmland area and its shape have similar characteristics of the area, patch density and shape of the tea plantation; they influence each other. The farmland area proportion (PLAND), the farmland patch density (PD) and the average farmland patch area (AM) have strong negative relation with the agglomeration index (AI) of the tea plantation. It means with the increasing farmland area, the patch density is increasing and its average area is bigger, but the agglomeration of the tea plantation is lower and lower. 


$$
-14905 \text { - }
$$

Table 2. Correlation analysis results between arable land and tea garden landscape pattern landscape class area (CA), proportion of landscape type area (PLAND), average patch area (AREA_MN), patch area standard deviation (AREA_SD), largest patch index (LPI), patch density (PD), landscape shape index (LSI), landscape agglomeration index (AI)

\begin{tabular}{|c|c|c|c|c|c|c|c|c|c|}
\hline & & $\begin{array}{c}\text { Farmlands } \\
\text { CA }\end{array}$ & $\begin{array}{c}\text { Farmlands } \\
\text { PLAND }\end{array}$ & $\begin{array}{c}\text { Farmlands } \\
\text { PD }\end{array}$ & $\begin{array}{c}\text { Farmlands } \\
\text { LPI }\end{array}$ & $\begin{array}{c}\text { Farmlands } \\
\text { LSI }\end{array}$ & $\begin{array}{c}\text { Farmlands } \\
\text { AM }\end{array}$ & $\begin{array}{c}\text { Farmlands } \\
\text { ASD }\end{array}$ & $\begin{array}{c}\text { Farmlands } \\
\text { AI } \\
\end{array}$ \\
\hline $\begin{array}{c}\text { Tea } \\
\text { plantation } \\
\text { CA }\end{array}$ & $p$ & $\begin{array}{c}0.907 * * \\
0.000\end{array}$ & $\begin{array}{l}-0.139 \\
0.667\end{array}$ & $\begin{array}{l}0.415 \\
0.179\end{array}$ & $\begin{array}{l}-0.406 \\
0.190\end{array}$ & $\begin{array}{c}0.930 * * \\
0.000\end{array}$ & $\begin{array}{l}-0.233 \\
0.467\end{array}$ & $\begin{array}{l}-0.342 \\
0.277\end{array}$ & $\begin{array}{l}-0.187 \\
0.560\end{array}$ \\
\hline $\begin{array}{c}\text { Tea } \\
\text { plantation } \\
\text { PLAND }\end{array}$ & $\mathrm{p}$ & $\begin{array}{c}0.883 * * \\
0.000\end{array}$ & $\begin{array}{l}-0.181 \\
0.574\end{array}$ & $\begin{array}{l}0.498 \\
0.099\end{array}$ & $\begin{array}{l}-0.457 \\
0.135\end{array}$ & $\begin{array}{c}0.966 * * \\
0.000\end{array}$ & $\begin{array}{l}-0.298 \\
0.346\end{array}$ & $\begin{array}{l}-0.395 \\
0.204\end{array}$ & $\begin{array}{l}-0.244 \\
0.445\end{array}$ \\
\hline $\begin{array}{c}\text { Tea } \\
\text { plantation } \\
\text { PD }\end{array}$ & $\mathrm{p}$ & $\begin{array}{c}0.800 * * \\
0.002\end{array}$ & $\begin{array}{l}-0.175 \\
0.587\end{array}$ & $\begin{array}{l}0.619 * \\
0.032\end{array}$ & $\begin{array}{l}-0.447 \\
0.145\end{array}$ & $\begin{array}{c}0.951 * * \\
0.000\end{array}$ & $\begin{array}{l}-0.326 \\
0.301\end{array}$ & $\begin{array}{l}-0.425 \\
0.168\end{array}$ & $\begin{array}{l}-0.297 \\
0.348\end{array}$ \\
\hline $\begin{array}{c}\text { Tea } \\
\text { plantation } \\
\text { LPI }\end{array}$ & $\mathrm{p}$ & $\begin{array}{c}0.637 * \\
0.026\end{array}$ & $\begin{array}{l}-0.142 \\
0.660\end{array}$ & $\begin{array}{l}0.158 \\
0.624\end{array}$ & $\begin{array}{l}-0.324 \\
0.304\end{array}$ & $\begin{array}{c}0.646 * \\
0.023\end{array}$ & $\begin{array}{l}-0.179 \\
0.577\end{array}$ & $\begin{array}{l}-0.253 \\
0.428\end{array}$ & $\begin{array}{l}-0.079 \\
0.806\end{array}$ \\
\hline $\begin{array}{c}\text { Tea } \\
\text { plantation } \\
\text { LSI }\end{array}$ & $\mathrm{p}$ & $\begin{array}{c}0.896 * * \\
0.000\end{array}$ & $\begin{array}{l}-0.223 \\
0.486\end{array}$ & $\begin{array}{l}0.511 \\
0.089\end{array}$ & $\begin{array}{l}-0.501 \\
0.097\end{array}$ & $\begin{array}{c}0.990 * * \\
0.000\end{array}$ & $\begin{array}{l}-0.333 \\
0.291\end{array}$ & $\begin{array}{l}-0.386 \\
0.216\end{array}$ & $\begin{array}{l}-0.239 \\
0.455\end{array}$ \\
\hline $\begin{array}{c}\text { Tea } \\
\text { plantation } \\
\text { AM }\end{array}$ & $\mathrm{p}$ & $\begin{array}{c}0.756 * * \\
0.004\end{array}$ & $\begin{array}{l}-0.512 \\
0.089\end{array}$ & $\begin{array}{l}-0.065 \\
0.841\end{array}$ & $\begin{array}{c}-0.667 * \\
0.018\end{array}$ & $\begin{array}{c}0.766 * * \\
0.004\end{array}$ & $\begin{array}{l}-0.501 \\
0.097\end{array}$ & $\begin{array}{l}-0.422 \\
0.171\end{array}$ & $\begin{array}{l}-0.246 \\
0.441\end{array}$ \\
\hline $\begin{array}{c}\text { Tea } \\
\text { plantation } \\
\text { ASD }\end{array}$ & $\mathrm{r}$ & $\begin{array}{c}0.764 * * \\
0.004\end{array}$ & $\begin{array}{l}-0.235 \\
0.463\end{array}$ & $\begin{array}{l}0.103 \\
0.749\end{array}$ & $\begin{array}{l}-0.430 \\
0.163\end{array}$ & $\begin{array}{c}0.743 * * \\
0.006\end{array}$ & $\begin{array}{l}-0.253 \\
0.428\end{array}$ & $\begin{array}{l}-0.284 \\
0.371\end{array}$ & $\begin{array}{l}-0.096 \\
0.766\end{array}$ \\
\hline $\begin{array}{c}\text { Tea } \\
\text { plantation } \\
\text { AI }\end{array}$ & $\mathrm{r}$ & $\begin{array}{l}0.492 \\
0.104\end{array}$ & $\begin{array}{c}-0.888 * * \\
0.000\end{array}$ & $\begin{array}{l}-0.361 \\
0.249\end{array}$ & $\begin{array}{c}-0.949 * * \\
0.000\end{array}$ & $\begin{array}{c}0.608 * \\
0.036\end{array}$ & $\begin{array}{c}-0.828 * * \\
0.001\end{array}$ & $\begin{array}{c}-0.646^{*} \\
0.023\end{array}$ & $\begin{array}{l}-0.528 \\
0.077\end{array}$ \\
\hline
\end{tabular}

r: correlation coefficient; p: significance

(2) The correlation of the forest land and the tea plantation landscape pattern is shown in Table 3. The bolded data means the variants have obvious relation at the layer of $\mathrm{p} \leq 0.01$. From Table 3, it is shown that as the elevation changes, the forest land area (CA), the shape index (LSI) and the tea plantation area (CA), the proportion of the tea plantation area (PLAND), the tea patch density (PD) and its shape index (LSI) have strong positive relation, and they have the same relation with the tea average patch area (AM) and the standard deviation of the tea patch area (ASD). So the forest land area and its shape have similar development trends of most tea plantation landscape index. They have strong influence on the landscape pattern of the tea plantation. The forest land area proportion (PLAND) and the agglomeration index (AI) of the tea plantation has strong negative relation, and the largest patch index (LPI) of the forest land is irrelevant with the AI of the tea plantation. Except the two negative relations, the other forest landscape indexes have very strong or strong positive relation with the AI of the tea plantation.

(3) The correlation of the grassland and the tea plantation landscape pattern is shown in Table 4. The bolded data means the variants have prominent relation at the layer of $\mathrm{p} \leq 0.01$. From Table 4, it is shown that as the elevation changes, the grass land area (CA) and the tea patch density (PD) have strong positive relation. It implies that the bigger the grassland area is, the denser and more fragmented the tea garden patches. The shape index and the agglomeration index of the grassland have strong positive relation with the agglomeration index of the tea garden. They influence each other and keep the same development trend. 


$$
-14906 \text { - }
$$

Table 3. Correlation analysis results between forest land and tea garden landscape pattern landscape class area (CA), proportion of landscape type area (PLAND), average patch area (AREA_MN), patch area standard deviation (AREA_SD), largest patch index (LPI), patch density (PD), landscape shape index (LSI), landscape agglomeration index (AI)

\begin{tabular}{|c|c|c|c|c|c|c|c|c|c|}
\hline & & $\begin{array}{c}\text { Forestlands } \\
\text { CA }\end{array}$ & $\begin{array}{c}\text { Forestlands } \\
\text { PLAND }\end{array}$ & $\begin{array}{c}\text { Forestlands } \\
\text { PD }\end{array}$ & $\begin{array}{c}\text { Forestlands } \\
\text { LPI }\end{array}$ & $\begin{array}{c}\text { Forestlands } \\
\text { LSI }\end{array}$ & $\begin{array}{c}\text { Forestlands } \\
\text { AM }\end{array}$ & $\begin{array}{c}\text { Forestlands } \\
\text { ASD } \\
\end{array}$ & $\begin{array}{c}\text { Forestlands } \\
\text { AI } \\
\end{array}$ \\
\hline \multirow{2}{*}{$\begin{array}{c}\text { Tea } \\
\text { plantation } \\
\text { CA }\end{array}$} & $\mathrm{r}$ & $0.922 * *$ & 0.285 & -0.356 & -0.080 & $0.829 * *$ & 0.304 & $0.633^{*}$ & 0.380 \\
\hline & $\mathrm{p}$ & 0.000 & 0.370 & 0.256 & 0.804 & 0.001 & 0.336 & 0.027 & 0.223 \\
\hline \multirow{2}{*}{$\begin{array}{c}\text { Tea } \\
\text { plantation } \\
\text { PLAND }\end{array}$} & $r$ & $0.901 * *$ & 0.302 & -0.322 & -0.058 & $0.882 * *$ & 0.255 & $0.587^{*}$ & 0.406 \\
\hline & $\mathrm{p}$ & 0.000 & 0.340 & 0.308 & 0.857 & 0.000 & 0.424 & 0.045 & 0.190 \\
\hline \multirow{2}{*}{$\begin{array}{c}\text { Tea } \\
\text { plantation } \\
\text { PD }\end{array}$} & $r$ & $0.818 * *$ & 0.267 & -0.228 & -0.089 & $0.872 * *$ & 0.155 & 0.454 & 0.371 \\
\hline & $\mathrm{p}$ & 0.001 & 0.401 & 0.476 & 0.784 & 0.000 & 0.631 & 0.138 & 0.236 \\
\hline \multirow{2}{*}{$\begin{array}{c}\text { Tea } \\
\text { plantation } \\
\text { LPI }\end{array}$} & $\mathrm{r}$ & $0.695^{*}$ & 0.246 & -0.342 & 0.034 & 0.571 & 0.284 & 0.549 & 0.328 \\
\hline & $\mathrm{p}$ & 0.012 & 0.441 & 0.277 & 0.916 & 0.052 & 0.371 & 0.065 & 0.297 \\
\hline \multirow{2}{*}{$\begin{array}{c}\text { Tea } \\
\text { plantation } \\
\text { LSI }\end{array}$} & $\mathrm{r}$ & $0.907 * *$ & 0.335 & -0.352 & -0.032 & $0.919 * *$ & 0.259 & $0.615^{*}$ & 0.466 \\
\hline & $\mathrm{p}$ & 0.000 & 0.288 & 0.262 & 0.922 & 0.000 & 0.416 & 0.033 & 0.127 \\
\hline \multirow{2}{*}{$\begin{array}{c}\text { Tea } \\
\text { plantation } \\
\text { AM }\end{array}$} & $\mathrm{r}$ & $0.864 * *$ & $0.624 *$ & $-0.696 *$ & 0.054 & $0.827 * *$ & $0.628^{*}$ & $0.810 * *$ & $0.697 *$ \\
\hline & $\mathrm{p}$ & 0.000 & 0.030 & 0.012 & 0.868 & 0.001 & 0.029 & 0.001 & 0.012 \\
\hline \multirow{2}{*}{$\begin{array}{c}\text { Tea } \\
\text { plantation } \\
\text { ASD }\end{array}$} & $\mathrm{r}$ & $0.826 * *$ & 0.364 & -0.476 & 0.049 & $0.693 *$ & 0.414 & $0.712 * *$ & 0.455 \\
\hline & $\mathrm{p}$ & 0.001 & 0.244 & 0.118 & 0.881 & 0.012 & 0.181 & 0.009 & 0.137 \\
\hline \multirow{2}{*}{$\begin{array}{c}\text { Tea } \\
\text { plantation } \\
\text { AI }\end{array}$} & $r$ & $0.704 *$ & $0.918 * *$ & $-0.913 * *$ & 0.177 & $0.810 * *$ & $0.837 * *$ & $0.762 * *$ & $0.962 * *$ \\
\hline & $\mathrm{p}$ & 0.011 & 0.000 & 0.000 & 0.582 & 0.001 & 0.001 & 0.004 & 0.000 \\
\hline
\end{tabular}

r: correlation coefficient; p: significance

Table 4. Correlation analysis results between forest grassland tea garden landscape pattern landscape class area (CA), proportion of landscape type area (PLAND), average patch area (AREA_MN), patch area standard deviation (AREA_SD), largest patch index (LPI), patch density (PD), landscape shape index (LSI), landscape agglomeration index (AI)

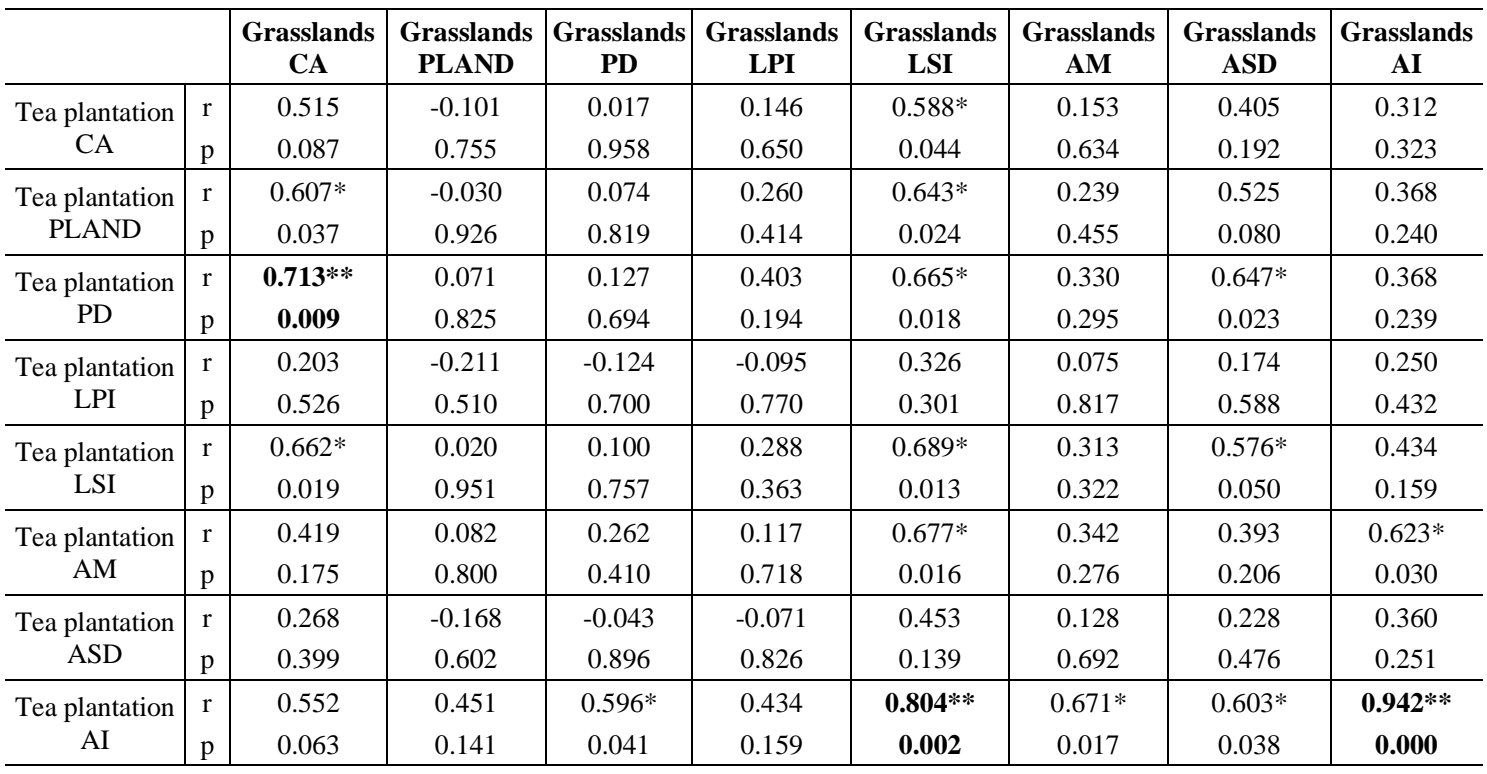

r: Correlation coefficient; p: Significance. 
(4) The correlation of the construction land and the tea plantation landscape pattern is shown in Table 5. The bolded data means the variants have more prominent relation at the layer of $\mathrm{p} \leq 0.01$. From Table 5 , it is shown that with the elevation change, the shape index (LSI) of the construction land has a very strong positive relation with the area (CA), the area proportion (PLAND), the patch density (PD) and the shape index (LSI) of the tea garden. The agglomeration index (AI) of the grassland has strong negative relation with most landscape indexes of the construction land.

Table 5. Correlation analysis results between forest construction tea garden landscape pattern landscape class area (CA), proportion of landscape type area (PLAND), average patch area (AREA_MN), patch area standard deviation (AREA_SD), largest patch index $(L P I)$, patch density (PD), landscape shape index (LSI), landscape agglomeration index (AI)

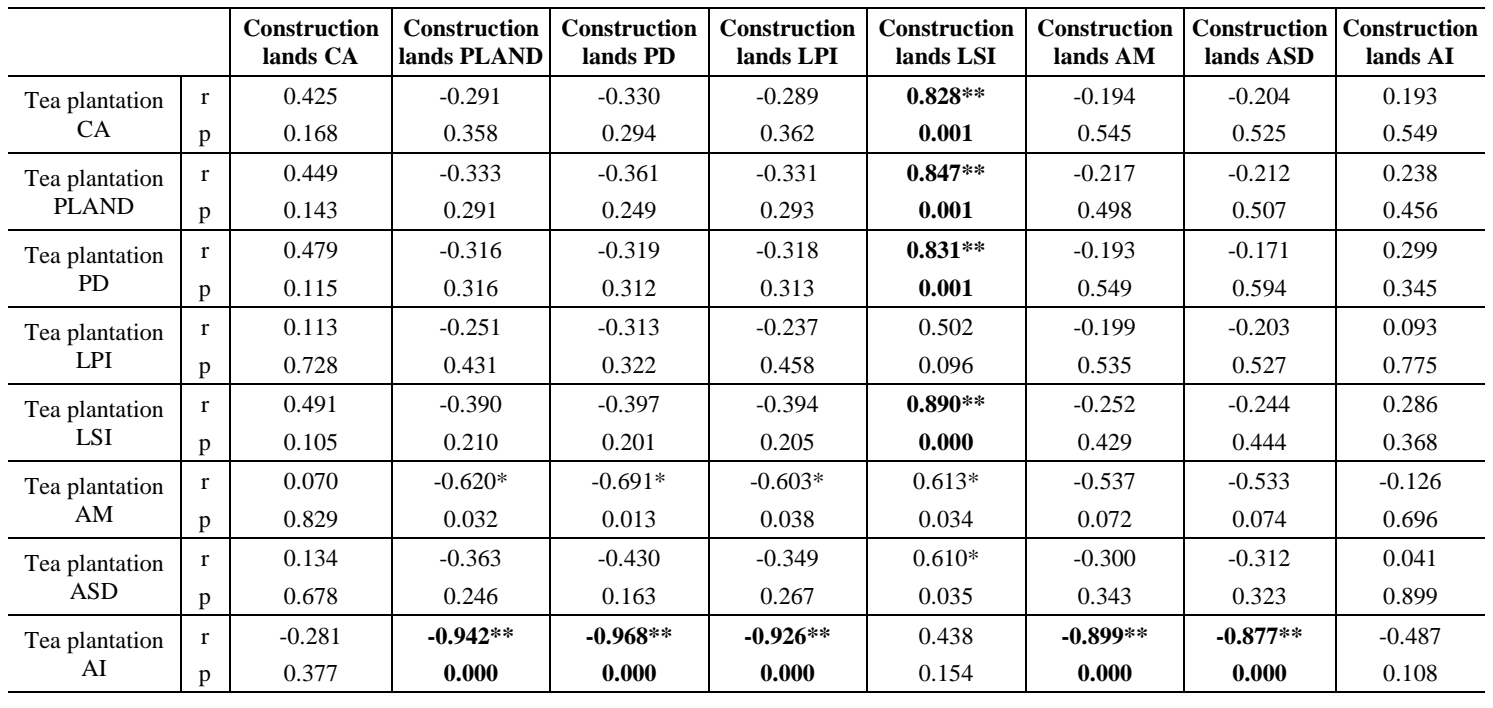

Notes: r: correlation coefficient; $\mathrm{p}$ : significance

\section{Discussion}

For the first time, the tea garden landscape pattern change under different land use and altitude gradient is studied for Lancangjiang Catchment (Yunnan Section). It lays a foundation for further research on the ecological environmental effect, and provides scientific basis for optimizing the land use landscape pattern in the catchment and improving the ecological environment of the catchment. However, there is some limitation of this study. Influenced by the resolution of the original remote sensing images, certain interpretation errors exist compared with the actual conditions. The temporal change is not studied due to large research area and time constraints, and only one-year data is studied at the macro level. More field investigation will be done in the future research to collect more information and data to make more accurate research results.

\section{Conclusions}

The landscape pattern characteristics of the tea garden under the four main types of the land use (farmland, forest land, grassland and the construction land) is studied from the aspect of the elevation gradient for the Lancangjiang Catchment (Yunnan Section). The study is done through the spatial, statistical and comparative analysis, and by the 
use of such geographical information and data analysis softwares as ENVI5.1, Arcgis10.0, Fragstats4.2 and Office 2007. The conclusions are made as follows:

(1) The eight landscape pattern indexes of the four main land use types express certain regularity with the altitude change. Their development trend is diverse and different.

(2) The landscape indexes of the tea plantation climb up first and then go down along the elevation gradient, with an invert "V" or invert " $U$ "-shape. The peak appears between 1200 and $1800 \mathrm{~m}$ where the tea planting is most active, and it implies that in this range, the tea garden is most extensively distributed, and it has the densest patches, the biggest scale change, the most complicated shapes and the highest spatial heterogeneity. The bottom value occurs below $600 \mathrm{~m}$ or above $2600 \mathrm{~m}$, and it implies that in this range, the tea garden is least distributed, and it has the least dense patches, the smallest scale change, the simpler shapes, the lowest agglomeration degree and the weaker spatial heterogeneity.

(3) Along the altitude gradient, there is a relatively strong correlation between the four main land use types and the tea garden landscape pattern, of which, the farmland and the forest land is most strongly correlated to the tea garden landscape, while the grassland is the weakest. Their correlation reflects in the characteristics of the three indexes such as the landscape area (CA), the landscape shape index (LSI) and the landscape agglomeration index (AI).

The next study will combine the temporal and spatial research and discuss the drivers of the change, to better comprehend the temporal change of the tea garden landscape, and its development trend and relationship with the ecological environment, and to provide the scientific basis for the ecological planting of the tea garden and improve the ecological environment of the catchment.

Acknowledgements. The research was supported by The National Natural Science Foundation Regional Science Foundation Project of China (No.41961040).

\section{REFERENCES}

[1] Biggs, E. M., Gupta, N., Saikia, S. D. (2018): The tea landscape of Assam: multistakeholder insights into sustainable livelihoods under a changing climate. Environmental Science \& Policy 82: 9-18.

[2] Cattarino, L., McAlpine, C. A., Rhodes, J. R. (2014): Land-use drivers of forest fragmentation vary with spatial scale. - Global Ecology and Biogeography 23(11): 12151224.

[3] Chen, B., Pu, H., Jiang, D., et al. (2011): Content and evaluation of heavy metal in soil of tea garden in Pu'er city. - Journal of Yunnan University (Natural Science Edition) 33(S2): 470-473 + 476 .

[4] Chen, L., Wang, R., Gao, M., et al. (2014): A GIS-based gradient analysis of land use landscape pattern changes. - Journal of Southwest University (Natural Science Edition) 36(5): 136-143.

[5] Chu, L., Zhang, X., Wang, T., et al. (2018): Spatial-temporal evolution and prediction of urban landscape pattern and habitat quality based on CA-Markov and in VEST model. Chinese Journal of Applied Ecology 29(12): 4106-4118.

[6] Fan, C., Tian, L., Shen, S., et al. (2018): Analysis on the landscape pattern change of the urban and green ecological space in Suzhou-Wuxi-Changzhou metropolitan area from 1990 to 2015. - Urban Research 11: 13-19. 
[7] Fan, N., Xie, G., Zhang, C., et al. (2012): Spatial-temporal dynamic changes of vegetation cover in Lancang River basin during 2001-2010. - Resources Science 34(7): 1222-1231.

[8] Furlanetto, L. M., Palma-Silva, C., Perera, M. B. (2018): Potential carbon gas production in southern brazil wetland sediments: possible implications of agricultural land use and warming. - Wetlands 38(3): 485-495.

[9] Gao, F., Li, G., Zhou, P., et al. (2013): Analysis on soil nutrients of tea gardens in Pu'er City of Yunnan Province. - Chinese Journal of Soil Science 44(2): 398-402.

[10] Gong, J., Hu, X., Peng, C., et al. (2010): The molecular composition and spectral properties of polysaccharide isolated from Pu-erh tea and its material. - Spectroscopy and Spectral Analysis 30(7): 1960-1964.

[11] Jaeschke, A., Rethemeyer, J., Lappe, M. (2018): Influence of land use on distribution of soil n-alkane delta D and brGDGTs along an altitudinal transect in Ethiopia: implications for (paleo) environmental studies. - Organic Geochemistry 124: 77-87.

[12] Li, Y., Liang, M., Xia, L., et al. (2011): Study on soil chemical constituents of the tableland tea garden in Yunnan Province. - Chinese Agricultural Science Bulletin 2: 171174.

[13] Liu, X., Gao, X., Gao, X., et al. (2008): Monitoring and pollution evaluation of heavy metals in the tea garden soils from main tea areas of Yunnan. - Journal of Anhui Agricultural Sciences 36(33): 14727-14728 + 14819 .

[14] Martyn, A., Barvinsky, A., Tykhenko, R. (2017): Problems of conceptual apparatus in environmental economics: relationship between the systems and mechanism of land use. - Zemleustrìj, Kadastr ì Monìtorìng Zemel 17(4): 21-28.

[15] Ning, J., Zhang, Z., Gu, X., et al. (2010): Fingerprint identification method of Pu'er raw tea based on high performance liquid chromatography profiles. - Transactions of the Chinese Society of Agricultural Engineering 26(3): 243-248.

[16] Ning, J., Wan, X., Zhang, Z., et al. (2013): Discriminating fermentation degree of Pu'er tea based on NIR spectroscopy and artificial neural network. - Transactions of the Chinese Society of Agricultural Engineering 29(11): 255-260.

[17] Pavani, B. F., Sousa, J., Wilson, C., Inouye, C. E. N. (2018): Estimating and valuing the carbon release in scenarios of land-use and climate changes in a Brazilian coastal area. Journal of Environmental Management 226: 416-427.

[18] Pu, J., Zhao, X., Gu, Z., et al. (2018): Landscape patterns and water quality changes in Qilu Lake basin of Yunnan Plateau. - Journal of Hydroecology 5: 13-21.

[19] Tan, C., Peng, C., Gao, B., et al. (2012): Spectroscopic and structural characteristics of the main components of theabrownin in Pirerh tea. - Spectroscopy and Spectral Analysis 32(4): 1051-1056.

[20] Wang, J., Cui, B., Liu, J., et al. (2008): The effect of land use and its change on ecological risk in the Lancang River watershed of Yunnan province at the landscape scale. - Journal of Environmental Sciences 28(2): 269-277.

[21] Yi, M., Li, X., Li, Y. (2011): Physical and chemical properties of soil in Pu-erh tea farms in Yunnan Province. - Journal of Beijing Normal University (Natural Science) 47(1): 8084.

[22] Zhai, J., Hou, P., Zhao, Z., et al. (2018): An analysis of landscape pattern spatial grain size effects in Qinghai Lake watershed. - Remote Sensing for Land \& Resources 30(3): 159-166.

[23] Zhang, J., Gao, R., Hu, J., et al. (2014): Application comparison of grey correlation degree and Pearson correlation coefficient. - Journal of Chifeng University (Natural Science Edition) 30(11): 1-2.

[24] Zhang, Y., Cai, X., Yang, C., et al. (2019): Driving force analysis of landscape pattern changes in Honghu Wetland Nature Reserve in recent 40 years. - Journal of Lake Science 31(1): 171-182. 


$$
-14910 \text { - }
$$

[25] Zhao, X., Liu, K., Qin, Y. (2007): Urban landscape pattern of Xi'an City based on GIS. Chinese Journal of Ecology 5: 706-711.

[26] Zheng, L., Zhao, Y., Feng, Y. (2013): Identification of Pu'er ripe teas with different origins and fermentation years by surface-enhanced Raman spectroscopy. - Spectroscopy and Spectral Analysis 6: 1575-1580. 